\title{
Differentiation of human epidermis-derived mesenchymal stem cell-like pluripotent cells into neural-like cells in culture and after transplantation
}

\author{
Min Zhang, Bing Huang*, Kaijing Li, Zhenghua Chen, Jian Ge, Weihua Li, Jianfa Huang, \\ Ting Luo, Shaochun Lin, Jie Yu, Wencong Wang, Liping Lin
}

State Key Laboratory of Ophthalmology, Zhongshan Ophthalmic Center, Sun Yat-sen University, Guangzhou, China;

*Corresponding Author: huangbing2000@hotmail.com

Received 11 August 2012; revised 12 September 2012; accepted 9 October 2012

\begin{abstract}
Skin is the largest organ of the human body and a possible source of stem cells for research and cell-based therapy. We have isolated a population of mesenchymal stem cell-like pluripotent cells from human epidermis, termed human (h) EMSCPCs. This preliminary study tested if these hEMSCPCs can be induced to differentiate into neural-like cells. Human EMSCPCs were first cultured for four to seven days in a serum-free neural stem cell (NSC) medium for pre-induction. During pre-induction, hEMSCPCs coalesced into dense spheres that resembled neural rosettes. In the presence of a conditioned differentiation medium, pre-induced cells took on the morphological characteristics of neural cells, including slender projections with inflated or claw-like ends that contacted the soma or projections of other cells as revealed by confocal microscopy. Moreover, these differentiating cells expressed the neural-specific markers $\beta$-III tubulin, MAP2, GFAP, and synapsin I as evidenced by immunocytochemistry. Both pre-induced hEMSCPCs and uninduced hEMSCPCs were labeled with CM-Dil and transplanted into the vitreous cavities of nude mice. Transplanted cells were examined four weeks later in frozen eyeball sections by immunofluorescence staining, which demonstrated superior retinal migration and neural differentiation of pre-induced cells. Our study is the first to demonstrate that hEMSCPCs possess the capacity to differentiate into neural-like cells, suggesting potential uses for the treatment of retinal diseases such as age-related macular degeneration.
\end{abstract}

Keywords: Human Epidermis; Pluripotent Cells;
Differentiation; Neural Cells; Cell Therapy

\section{INTRODUCTION}

Neurological degenerative diseases like Alzheimer's disease, Parkinson's disease, and age-related macular degeneration are a group of chronic, diverse and progressive disorders. Studies have shown heredity, oxidative stress, neurotrophic factor deficiency, dysbolism and other unknown factors could cause a main pathological change of special neurons degeneration and loss, followed by demyelination of nerve fibers [1]. These pathophysiology leads to a decreased activity in the pathway of neural conduction, and results in disturbance of memory, learning, moving and other activities, which causes severe public health burden, particularly in an aging population. Current treatments for these diseases include neuroprotective agents, surgery, physical stimulation, gene therapy, and cell replacement [2-4]. However, pharmacologic, surgical, and physical therapies cannot cure these diseases. Recent reports have shown that gene and cell-replacement therapies are promising alternatives for treating or even curing neurological disorders [5-7]. However, the complexity of the human genome and proteome limits the therapeutic effects of single gene therapy. Indeed, the results of clinical trials testing single gene therapies for Parkinson's disease were less than ideal [8-9].

Theoretically, cell-replacement therapy can cure neurodegenerative diseases by replacing lost cells and reconstructing tissues, leading to functional recovery. Multipotent stem cells are widely used for research on cellreplacement therapy and can be derived from both the embryo (embryonic stem cells, ESCs) and adult tissue (adult stem cells, ASCs). The strong plasticity of ASCs enables directional differentiation into multiple cell types. Numerous studies have revealed that ESCs, neural stem cells (NSCs), bone marrow stem cells (BMSCs), and 
precursor cells derived from peripheral blood, umbilical cord blood, and fat tissue can differentiate into neural cells [10-17]. However, there are ethical issues surrounding the harvesting of ESCs; moreover, these cells are potentially oncogenic [18-19]. Neural stem cells exist in several adult human tissues but are difficult to isolate [20]. The process of isolating BMSCs is invasive and painful, and the quantities obtained are generally not sufficient for therapeutic applications [21]. Moreover, more accessible peripheral blood and umbilical cord blood contain relatively low numbers of precursor cells, and it is still disputed whether these precursor cells can integrate with the host tissue and differentiate into the appropriate cell types after transplantation [22-24]. Although fat tissue is easily extracted, techniques for the isolation and purification of precursor cells from adipose tissue are still not fully developed [25].

Skin is the largest human organ and its cells are easily harvested. Several groups have isolated pluripotent cells from mammalian skin that can differentiate into neural cells [26-32]. After transplantation into animal models, these skin-derived pluripotent cells were able to promote nerve regeneration and functional improvement after injury [33-36]. It is known that epidermal stem cell-like pluripotent cells are present in the epidermal-basal layer and function in the repair and regeneration of the epidermis [37-38]. We have isolated a population of mesenchymal stem cell-like pluripotent cells from mixed cultures of human epidermal cells that we refer to as human epidermis-derived mesenchymal stem cell-like pluripotent cells (hEMSCPCs) (national patent number: 201010282388.0) [39]. In this exploratory study, we examined whether hEMSCPCs have the capacity to differentiate into neural-like cells. Our data revealed that hEMSCPCs can be induced to differentiate into cells with neural cell characteristics in vitro and express some neural cell-specific markers in vivo when transplanted into the mouse eye, suggesting the hEMSCPCs may be used for autologous cell-based therapies to treat neurological disorders.

\section{MATERIALS AND METHODS}

\subsection{Isolation of hEMSCPCs and Cultured in Growth Medium}

The hEMSCPCs were isolated from foreskin tissue obtained from circumcision surgery. Tissue donors were healthy as defined by normal blood and urine test results, normal liver and lung function, no history of genetic disease, and the absence of current infectious disease. Written informed consent was provided by the participants. The study was approved by the Medical Ethics Committee of Zhongshan Ophthalmic Center, Sun Yatsen University (No. 2008-30).
Briefly, foreskin tissue was rinsed in phosphate buffered saline (PBS) containing gentamycin $(1000 \mathrm{U} / \mathrm{ml})$ for subsequent treatment, the tissue was cut into pieces of 3 $\mathrm{mm} \times 3 \mathrm{~mm}$ in size using scalpes and transferred into a sterilized $15 \mathrm{ml}$ centrifugation tube. Then Dispase II (2 $\mathrm{U} / \mathrm{ml}$; GIBCO, USA) was added into the tube, incubated at $6^{\circ} \mathrm{C}-8^{\circ} \mathrm{C}$ for 15 hours and then $37^{\circ} \mathrm{C}$ for 1 hour to remove the dermis. The epidermis were transferred into a new sterilized $15 \mathrm{ml}$ centrifugation tube, washed with PBS for 5 times and crushed. Then suspended with PBS containing $0.25 \%$ trypsin and gently pippetted, incubated at $37^{\circ} \mathrm{C}$ for $30 \mathrm{~min}$. Then washed with PBS twice more and centrifugated at $1200 \mathrm{rpm}$ for $5 \mathrm{~min}$, discarded the supernatant. Cell precipitation was suspended in growth medium consisting of $80 \%$ DMEM (GIBCO, USA), 18\% fetal bovine serum (FBS) (Si Jiqing Ltd., China), $10 \mathrm{ng} / \mathrm{ml}$ basic fibroblast growth factor (bFGF) (PERPO-TECH, USA), $2 \mathrm{ng} / \mathrm{ml}$ stem cell factor (SCF) (PERPO-TECH, USA), and 1\% MEM nonessential amino acids (NEAA) $(100 \times$ solution, GIBCO, USA), and plated in T-25 cell culture flask, incubated at $37^{\circ} \mathrm{C}$ in a $5 \% \mathrm{CO}_{2}$ atmosphere. The flask remained unmoved within 48 hours, then the medium was replaced according to the rate of cell growth, and the un-adherent cells were removed. Ten days later, small hEMSCPCs appeared; three weeks later, they were deplated using $0.25 \%$ trypsin- $0.02 \%$ ethylene diamine tetraacetic acid (EDTA) and passaged at 1:3. They were continuously cultured and passaged over 30 times in vitro [39]. The hEMSCPCs from passages 17 to 19 derived from same biopsy (fore-skin of a 21-year-old male) were used for this study.

Cryopreserved hEMSCPCs were resuscitated from liquid nitrogen and suspended in growth medium (mentioned above). Cell suspensions $\left(8 \mathrm{ml}\right.$ of $1.0 \times 10^{4}$ cells/ $\mathrm{ml}$ ) were plated in $\mathrm{T}-25$ cell culture flasks and incubated at $37^{\circ} \mathrm{C}$ in a $5 \% \mathrm{CO}_{2}$ atmosphere. The medium was replaced according to the rate of cell growth. When cells reached confluence, the hEMSCPCs were deplated using $0.25 \%$ trypsin- $0.02 \%$ EDTA and passaged at 1:3. Cultures were observed and photographed using an inverted microscope (Leica DMIRB, Germany).

\subsection{Pre-Induction Culture of hEMSCPCs in NSC Medium}

For pre-induction, hEMSCPCs were deplated and suspended in NSC medium consisting of $96 \%$ DMEM/ F12 (GIBCO, USA), 2\% B27 (GIBCO, USA), $20 \mathrm{ng} / \mathrm{ml}$ bFGF (PERPOTECH, USA), $20 \mathrm{ng} / \mathrm{ml}$ epidermal growth factor (EGF) (PERPOTECH, USA), $2 \mathrm{ng} / \mathrm{ml} \mathrm{SCF} \mathrm{(PER-}$ POTECH, USA), and 1\% MEM NEAA $(100 \times$ solution, GIBCO, USA). Cell suspensions ( $8 \mathrm{ml}$ of $1.0 \times 10^{4}$ cells $/ \mathrm{ml}$ ) were replated in $\mathrm{T}-25$ cell culture flasks and incubated at $37^{\circ} \mathrm{C}$ under $5 \% \mathrm{CO}_{2}$. The medium was re- 
placed everyday. Cultures were observed and photographed as described above.

\subsection{Differentiation of hEMSCPCs in Conditioned Differentiation Medium}

After 6 days, the NSC medium was replaced with a conditioned differentiation medium consisting of $88 \%$ DMEM/F12 (GIBCO, USA), 10\% FBS (Si Jiqing Ltd., China), $20 \mathrm{ng} / \mathrm{ml} \mathrm{bFGF}$ (PERPOTECH, USA), $20 \mathrm{ng} / \mathrm{ml}$ EGF (PERPOTECH, USA), and 1\% MEM NEAA (100 $\times$ solution, GIBCO, USA). Cells were incubated for 1 or 3 weeks depending on the experiment. In addition, hEMSCPCs cultured in growth medium but not pre-induced in NSC medium were cultured in differentiation medium as a control. Cultures were observed and photographed under an inverted microscope (Leica DMIRB, Germany). The hEMSCPCs pre-induced in the NSC medium grew slender projections during differentiation, so some cultures were plated at lower density $\left(1.0 \times 10^{3}\right.$ cells $\left./ \mathrm{ml}\right)$ to aid in morphological observation.

\subsection{Subculturing for Immunofluorescence and CM-Dil Staining}

To detect the expression of cell-specific markers in hEMSCPCs during differentiation, cells were seeded onto cover slips and immunostained (below). Other cultures were labeled with CM-DiI to observe cell-cell contacts. Seeded cover slips were divided into five groups of 10 slides each. The hEMSCPCs cultured in the growth medium but not pre-induced by NSC medium constituted group A (GM, control). The hEMSCPCs cultured in growth medium and then pre-induced in the NSC medium for six days constituted group B (GM + NSC). Human EMSCPCs cultured in growth medium, pre-induced in NSC medium for six days, and then cultured in the conditioned differentiation medium for three weeks were group C (GM + NSC + CM 3 weeks). Human EMSCPCs cultured in the growth medium but not pre-induced in the NSC medium for six days before culture in the conditioned differentiation medium for three weeks were group D (GM + CM 3 weeks) and served as the control for group C. Group E consisted of hEMSCPCs cultured in growth medium, pre-induced in the NSC medium for six days, and then cultured in the conditioned differentiation medium for one week (GM + NSC + CM 1 week). At the beginning, cell densities of group A and group B were adjusted to $1.0 \times 10^{4}$ cells $/ \mathrm{ml}$, while those of groups $\mathrm{C}, \mathrm{D}$, and $\mathrm{E}$ were adjusted to $1.0 \times 10^{3}$ cells $/ \mathrm{ml}$ for improved morphological observation of differentiating cells. Human EMSCPCs suspensions were plated onto sterile $22 \times 22 \mathrm{~mm}^{2}$ cover slips in $35 \mathrm{~mm}$ culture dishes. Each culture dish contained one hEMSCPCs cover slip. All cultures were incubated at $37^{\circ} \mathrm{C}$ under $5 \% \mathrm{CO}_{2}$. After the treatments described above, cover slips were collected for staining. Groups A, B, C, and D cells were stained by immunofluorescence and group E cultures were labeled with CM-DiI.

\subsection{CM-Dil Labeling of the Differentiating hEMSCPCs}

Cells were labeled with CM-DiI rather than processed for electron microscopy (EM) because EM fixation and processing/staining tend to cause contraction of processes [40,41]. Furthermore, EM is laborious and expensive. In contrast, CM-DiI is a lipid-soluble biomembrane stain that allows for clear visualization of cell morphology and cell-cell contacts [42].

Ten hEMSCPCs-seeded cover slips of group E (defined above) were collected, washed twice in PBS, and stained with $5 \mu \mathrm{l} / \mathrm{ml}$ CM-DiI (Molecular Probes, USA) in $200 \mu \mathrm{l}$ PBS for $3 \mathrm{~min}$ at $37^{\circ} \mathrm{C}$. Stained cover slips were washed twice quickly in PBS and then fixed in 4\% paraformaldehyde for $40 \mathrm{~min}$. The nuclei were counterstained by Hoechst (Sigma, USA) for $5 \mathrm{~min}$ at room temperature (RT). Slides were then treated by an anti-fade solution (Applygen, China) and imaged under a laser confocal scanning microscope (Zeiss, Germany). Ten different visual fields were observed in each cover slip.

\subsection{Immunofluorescence Staining of hEMSCPCs Cultured in Vitro}

Immunofluorescence staining was used to detect the expression of cell-specific antigens in hEMSCPCs cultured in vitro. The hEMSCPCs-seeded cover slips of groups A, B, C, and D were collected and fixed in $4 \%$ paraformaldehyde for $15 \mathrm{~min}$, permeabilized in $0.3 \%$ Triton-X for $15 \mathrm{~min}$, and then incubated at $37^{\circ} \mathrm{C}$ for 40 min in the following primary antibodies: human nestin, MAP2, synapsin I (Abcam, USA), vimentin (ZSGB-BIO, China), $\beta$-III tubulin (Millipore, USA), and GFAP (Eptomics, USA). Slides were then incubated in secondary antibodies, either Cy3-conjugated goat anti-mouse (Millipore, USA) or FITC-conjugated goat anti-rabbit (Southern Biotech, USA) for $30 \mathrm{~min}$ at RT. The nuclei were stained by Hoechst (Sigma, USA) for 5 min at RT, and then all slides were treated with an anti-fade solution (Applygen, China) and imaged under a laser confocal scanning microscope (Zeiss, Germany). Ten different visual fields were observed in each cover slip.

\subsection{Flow Cytometry}

Flow cytometry was used to quantify the expression of cell-specific markers in GM + NSC 4 days and GM hEMSCPCs groups. Both direct labeling and indirect labeling were used. Antibodies used for direct labeling were specific for human CD73 and its PE-iso-type con- 
trol (BD, USA). Primary antibodies used for indirect labeling were specific for human nestin (Abcam, USA), vimentin (ZSGB-BIO, China), MAP2, and GFAP (Abcam, USA). The secondary antibodies were R-PE-conjugated goat anti-mouse and FITC-conjugated goat anti-rabbit (Southern Biotech, USA). Fix and Perm Cell Permeabilization reagents (Invitrogen, USA) were used for labeling intracellular antigens. Cell suspensions were stained and counted by flow cytometry according to the manufacturer's directions. Cell suspensions treated with secondary antibodies but not primary antibodies served as iso-type controls for indirect labeling. Cell suspendsions were tested immediately by flow cytometry (BD FACSAria $^{\mathrm{TM}}$, USA) using FCS Express V3 software for data analysis. The positive value of iso-type controls was maintained at $0 \%$ to $1 \%$.

Prior to cell transplantation in vivo (below), the expression levels of immunogenic markers (HLA-I and HLA-DR) in GM + NSC 4 days and GM hEMSCPCs were first detected by direct labeling and flow cytometry. Cell suspensions were treated with antibodies specific for human HLA-I (Invitrogen, USA), HLA-DR, and their FITC-iso-type control (BD, USA). Protocols were in accordance with the manufacturer's directions.

\subsection{Transplantation of hEMSCPCs into the Vitreous Cavities of Nude Mice}

The retina, an extension of the central nervous system containing a variety of highly differentiated cell types, was chosen to provide the internal microenvironment for hEMSCPCs differentiation. Human EMSCPCs were transplanted into the vitreous cavities of nude mice, and migration and differentiation were observed after four weeks.

The GM + NSC 4 days and GM cultures were termed groups $\mathrm{A}$ and $\mathrm{B}$ in the transplantation study. Before transplantation, both groups were labeled by CM-DiI (Molecular Probes, USA) according to the manufacturer's instructions. In addition, one $500 \mu 1$ sample from each cell suspension labeled by CM-DiI was analyzed by flow cytometry to test CM-DiI labeling efficiency. Cell suspensions $\left(1 \times 10^{7}\right.$ cells $\left./ \mathrm{ml}\right)$ with high labeling efficiency were immediately injected into the eyes of nude mice.

Sixteen 6-week-old BLAB/c nude mice of both genders were provided by the Laboratory Animal Center, Sun Yat-sen University (Quality certificate number: 0061839). The mice were cared for in accordance with the Regulations on Administration of Experimental Animals in Guangdong Province, China. They were housed in the specific pathogen-free (SPF) area of the Ophthalmology Animal Experimental Center, ZhongShan Ophthalmic Center, Sun Yat-sen University, with a 12 h lightdark cycle $\left(23^{\circ} \mathrm{C}-25^{\circ} \mathrm{C}\right.$, humidity $\left.55 \%\right)$. These trans- plantation experiments were approved by the Laboratory Animal Administration and Ethics Committee of Zhongshan Ophthalmic Center, Sun Yat-sen University (No. 2010-024). The 16 nude mice were randomly divided into three groups (group A, B, and C), each with a 1:1 sex ratio. The right eyes of all group $A(n=6)$ mice were injected with hEMSCPCs that had been pre-induced in the NSC medium for four days, while the right eyes of group B were injected with hEMSCPCs cultured in the growth medium but not pre-induced by NSC medium. The remaining four mice (group C) served as normal controls.

Before transplantation, experimental mice were anesthetized by intraperitoneal injection of $4.3 \%$ chloral hydrate $(0.01 \mathrm{ml}$ per $1 \mathrm{~g}$ body weight $)$ obtained from the Ophthalmologic Hospital, Sun Yat-sen University. Tobramycin eye drops were used to disinfect the experimental eye, followed by dicaine hydrochloride eye drops (both drugs obtained from the Ophthalmologic Hospital, Sun Yat-sen University) for superficial anesthesia. A 1-ml-injector needle was used to pierce the central cornea and drain part of the aqueous humor to lower the intraocular pressure. Under an operating microscopy (Topcon, Japan), a second 1-ml injector containing $10 \mu \mathrm{l}$ of either cell suspension (pre-induced with NSC medium or untreated) was placed $1 \mathrm{~mm}$ outside the corneoscleral junction on the temporal side. The needle penetrated at a $15^{\circ} \mathrm{C}$ acute angle relative to the eyeball coronal plane. When the needle reached the vitreous cavity, cell suspendsions were injected. The needle was immediately withdrawn at the first signs of eyeball puffing. The experimental eye was then washed with tobramycin eye drops, followed by tobramycin eye ointment. All procedures were performed in the SPF area operating room. Appropriate body temperature was maintained during the operation and intraoperative animal care conformed to institutional guidelines. After mice regained consciousness, they were sent back to the feeding room. To prevent infection, tobramycin eye drops were applied three times daily for three days after the operation.

\subsection{Frozen Eyeball Sectioning and Immunofluorescence Staining}

Four weeks after cell transplantation, all the mice were anesthetized by intraperitoneal injection of $4.3 \%$ chloral hydrate and sacrificed by cervical dislocation. All right eyes were enucleated, frozen in OCT embedding compound (Sakura, USA), and stored at $-20^{\circ} \mathrm{C}$ before cryostat sectioning at $6 \mu \mathrm{m}$ on a freezing microtome (Leica, Germany). Sections were then processed for immunofluorescence labeling as described (see Immunofluorescence staining of hEMSCPCs cultured in vitro). Primary antibodies were specific for human nestin, MAP2, rhodopsin (Abcam, USA), $\beta$-III tubulin (Sigma, USA), 
and GFAP (Epitomics, USA). An FITC-conjugated goat anti-rabbit antibody (Southern Biotech, USA) was used for fluorescence tagging. The migration and differentiation of the transplanted hEMSCPCs in nude mice were examined by laser confocal scanning microscopy (Zeiss, Germany). Ten different visual fields were observed in each section.

\subsection{Statistical Analysis}

Analysis of variance (ANOVA) with repeated measures was used to compare treatment means. A value of $P$ $<0.05$ was considered statistically different. The SPSS v13.0 software package was used for all statistical analyses.

\section{RESULTS}

\subsection{Morphology of hEMSCPCs Cultured in Growth Medium}

When cultured in growth medium, hEMSCPCs appeared as small spindle-shaped cells that adhered to the bottoms of culture flasks in a monolayer arranged in a vortex pattern (Figures 1(A) and (B)). They proliferated rapidly in growth medium; when seeded at $1.0 \times 10^{4}$ cells $/ \mathrm{ml} \times 8 \mathrm{ml}$ in $\mathrm{T}-25$ plastic culture flasks, they reached confluence in two days [39].

\subsection{Changes in hEMSCPCs Morphology during Pre-Induction in NSC Medium}

To direct hEMSCPCs toward the neuronal lineage, we provided a conducive environment using a neural stem cell (NSC) medium. One day after culture in NSC medium, the hEMSCPCs somata aggregated to form small dense light-reflective spheres that were fully or partly adherent to the bottoms of the flasks. A few small spindle-shaped cells began to stretch out from the edges of the spheres (Figures 1(C) and (D)). After three days in NSC medium, many spindle-shaped cells stretched out from the edges of the spheres and formed strongly light reflective rosette-shaped clusters at the edges (Figures 1(E) and (F)). As days went on, the spindle-shaped cells stretched out further and the rosettes enlarged (Figures 1(G) and (H)).

\subsection{Changes in hEMSCPCs Morphology during Culture in Conditioned Differentiation Medium as Revealed by Light Microscopy}

At day 6, NSC medium was replaced with a conditioned differentiation medium. Within one day, most cells began to grow one or more slender projections that resembled neurites (Figures 2(B)- (D)). Three days later, as these projections became longer and continued to extend, contacts were formed between cells (Figures 2(E)-(G)). After one week in conditioned medium, the projections continued to extend and branches emerged at the ends (Figure 2(H)). In contrast, hEMSCPCs cultured in the growth medium but not in NSC medium showed no obvious changes in morphology during incubation in the conditioned differentiation medium (Figure 2(A)).

\subsection{Changes in hEMSCPCs Morphology during Culture in Conditioned Differentiation Medium as Revealed by CM-Dil Labeling}

To examine cell morphology and cell-cell contacts in detail, cultures were stained with the membrane dye CM-DiI and viewed under laser confocal scanning microscopy. The profiles of differentiated hEMSCPCs were clearly distinguished by CM-DiI, including cell bodies and slender projections that exhibited inflated ends or even claw-like ends (Figures 3(A)-(C)). Many of these CM-DiI-labeled differentiated cells contacted each other, either through projection-soma or projection-projection contacts (Figures 3(A)-(C)).

\subsection{Immunofluorescence Staining of Cultured hEMSCPCs}

Immunofluorescence staining was used to detect the expression of cell-specific markers during culture in the three culture media (growth, NSC, and conditioned differentiation media). When cultured only in the growth medium, hEMSCPCs were positive for the NSC marker nestin as well as the neural precursor cell and mesenchymal cell marker vimentin (Figures 3(D) and (E)), but negative for neural cell markers $\beta$-III tubulin, microtubule-associated protein-2 (MAP2), glial fibrillary acidic protein (GFAP), and the synaptic marker synapsin I (data not shown). After pre-induction in the NSC medium, the expression of these markers was not significantly changed, though cells remained positive for nestin and vimentin (Figure 3(F)). Consistent with the marked morphological transformation (Figures 2 and 3(A)-(C)), cells cultured in the conditioned differentiation medium following pre-induction in NSC medium expressed neural cell markers $\beta$-III tubulin, MAP2, GFAP, and synapsin I (Figures 3(G)-3(J)). In contrast, hEMSCPCs cultured in the growth medium but not pre-induced in NSC medium did not express these neural cell markers during culture in conditioned differentiation medium (data not shown).

\subsection{Flow Cytometry Analysis}

Flow cytometry was used to quantify the different protein expression phenotypes. During culture in growth medium, most hEMSCPCs stably expressed the mesen- 

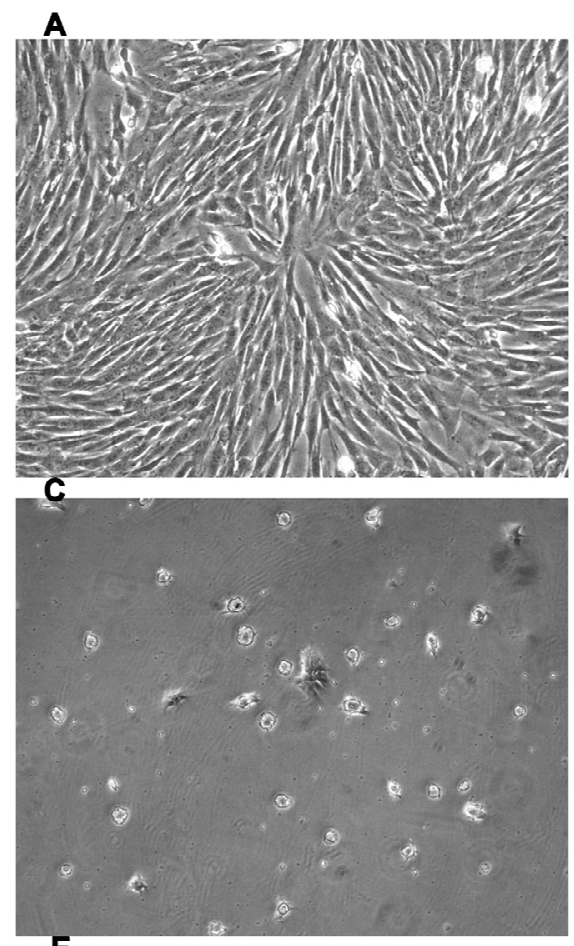

B
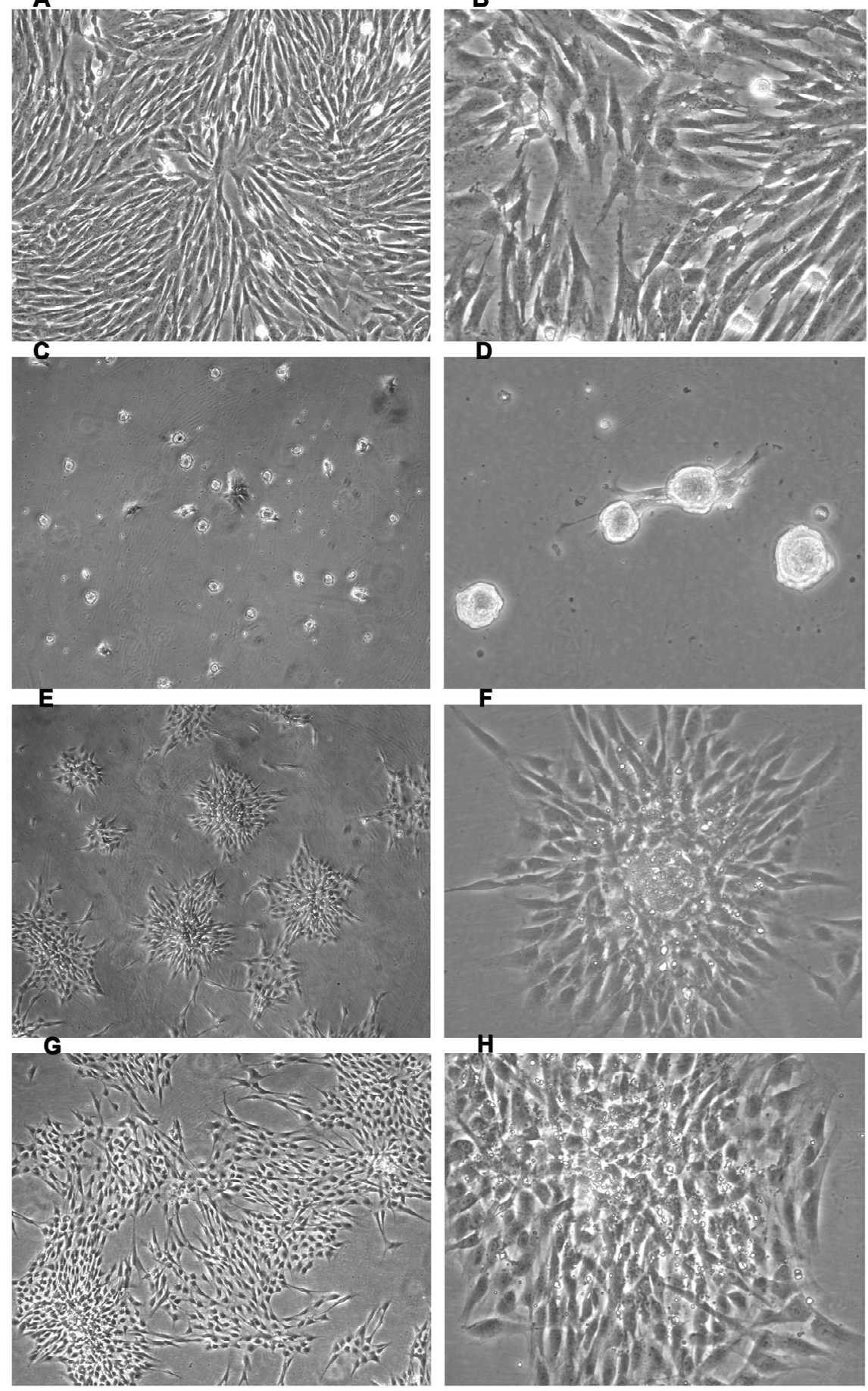

Figure 1. Morphological changes of hEMSCPCs during culture in growth medium and NSC medium. (A) and (B) The morphology of hEMSCPCs cultured in growth medium. Plated cells formed monolayers in a vortex pattern within two days $((\mathrm{A})$, magnification $\times 50$; $(\mathrm{B})$, magnification $\times 200)$. $(C)-(H)$ Change in morphology during pre-induction in NSC medium. One day after changing to the NSC medium, hEMSCPCs formed small dense spheres and a few small spindle-shaped cells began to stretch out from the edges $((C)$, magnification $\times 50$; (D), magnification $\times 200$ ). After three days in NSC medium, many spindle-shaped cells stretched out from the spheres $((\mathrm{E})$, magnification $\times 50$; $(\mathrm{F})$, magnification $\times 200)$. After six days, many cells were observed migrating outward $((\mathrm{G})$, magnification $\times 50 ;(\mathrm{H})$, magnification $\times 200$ ). 
A

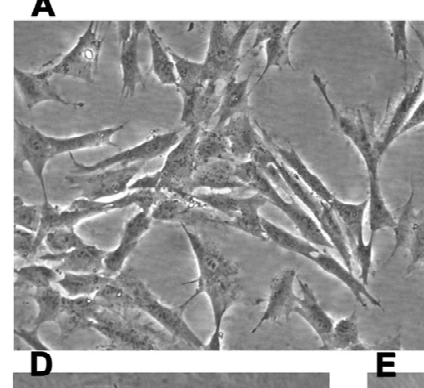

B
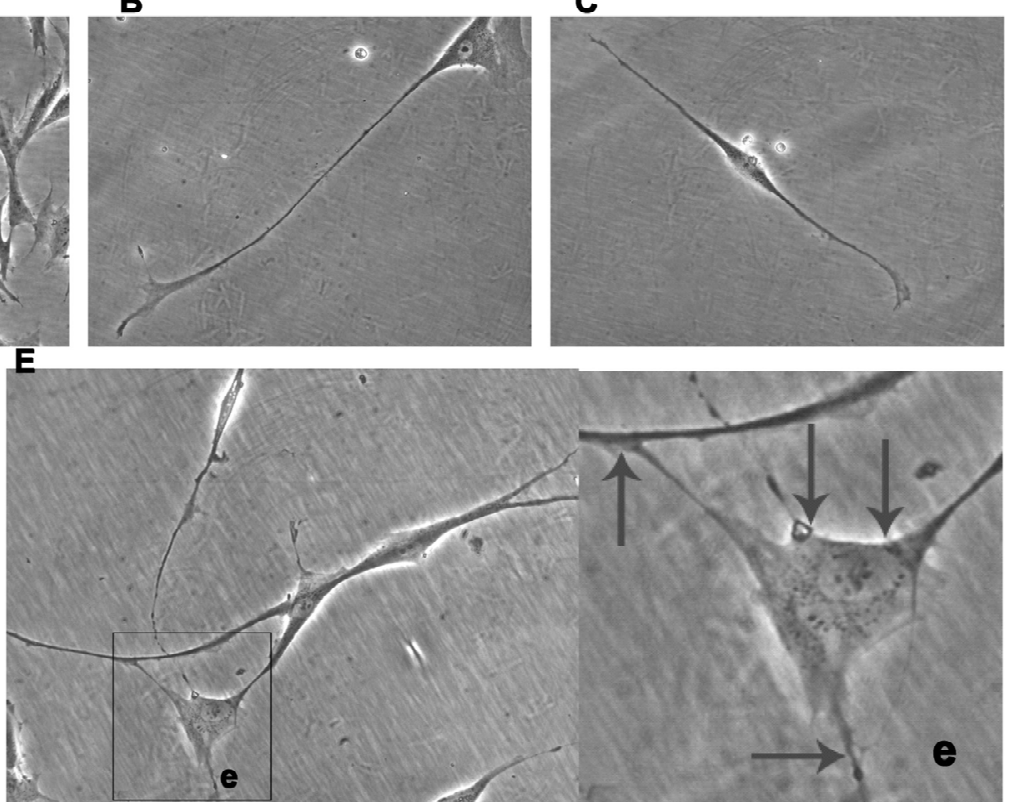

F

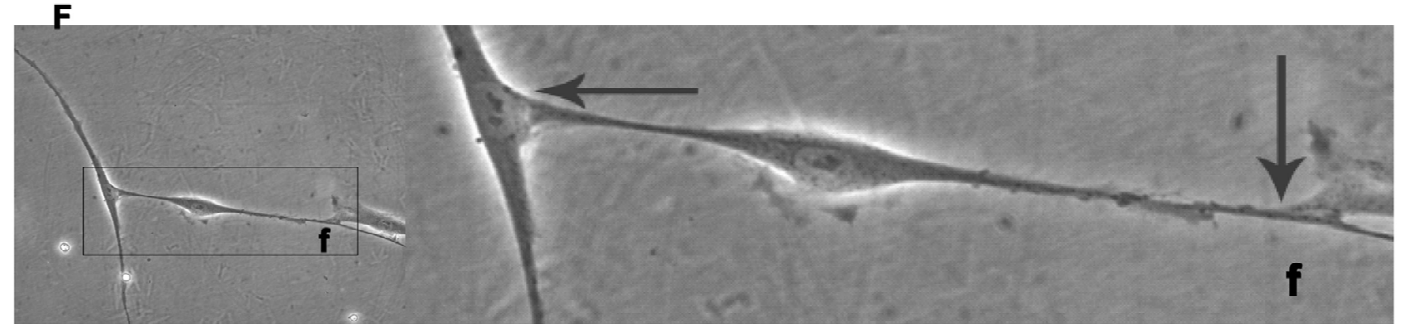

G

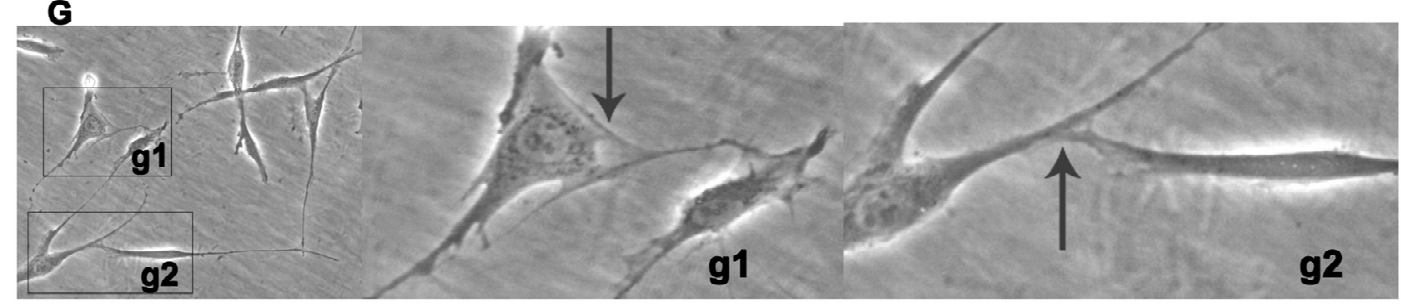

H

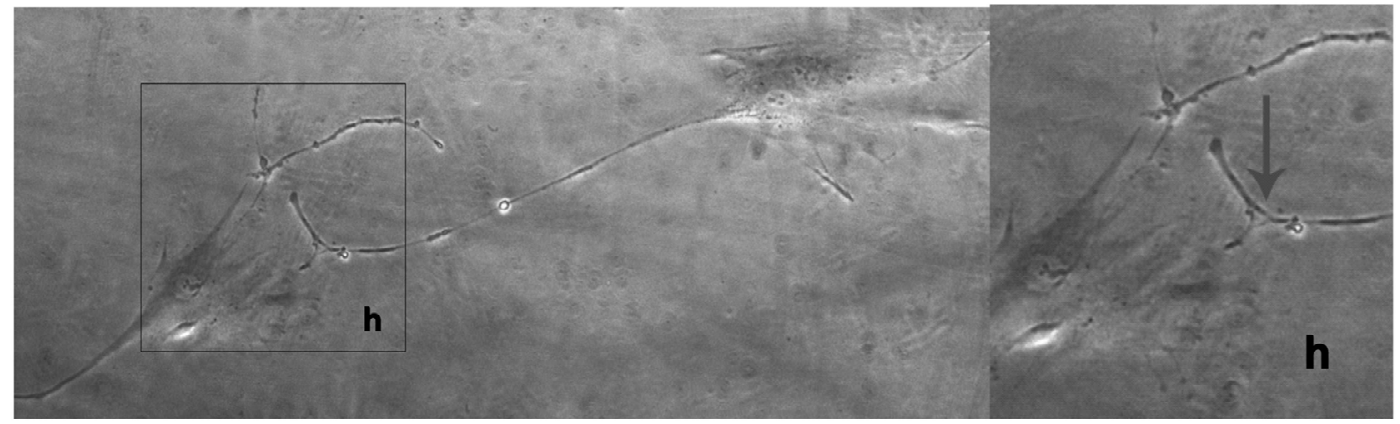

Figure 2. Morphology of hEMSCPCs during culture in conditioned differentiation medium. (A) Human EMSCPCs not pre-induced in NSC medium showed no significant changes in morphology when cultured in the conditioned differentiation medium (magnification $\times 200)$. (B)-(H) After one day in the conditioned differentiation medium, hEMSCPCs that were pre-induced began to grow one (B), two (C) or more (D) slender projections (magnification $\times 200$ ); $(\mathrm{E})-(\mathrm{G})$ After three days in conditioned differentiation medium, these projections were longer and continued to extend toward neighboring cells. Contacts (red arrows) were formed between cells (magnification $\times 200$; (e), (f), (g1), and (g2) are the magnified boxed areas in panels (E), (F), and (G). (H) After one week, the projections continued to extend and branches (red arrows) formed at the ends (magnification $\times 100$, $\mathrm{h}$ is the magnified region in $(\mathrm{H})$ ). 

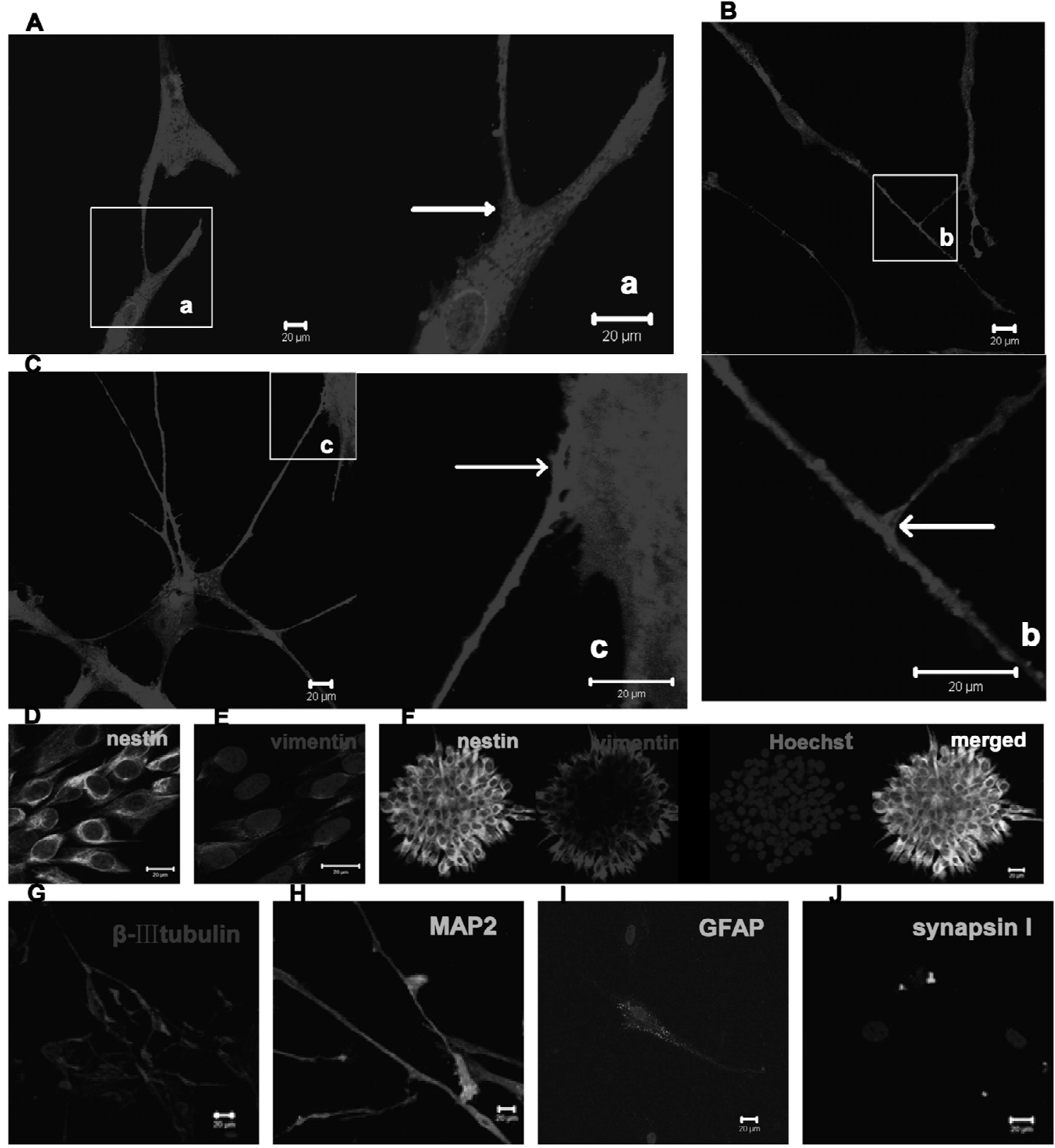

Figure 3. CM-DiI labeling of differentiating hEMSCPCs and immunofluorescence staining of hEMSCPCs cultured in vitro. (A)-(C) The profile of differentiated hEMSCPCs labeled by red CM-DiI, showing cell bodies and slender projections with inflated or claw-like ends (white arrows in (C)). These CM-DiI-labeled differentiated cells contacted each other and CM-DiI-labeled cell membranes could be seen between these contacts (white arrows) ((a), (b), and (c) are high magnification zones from panels (A), (B), and (C)). (D)-(E) When cultured in growth medium, many hEMSCPCs were positive for nestin ((D), green) and vimentin ((E), red). (F) After pre-induction in NSC medium, cells were also positive for nestin (green) and vimentin (red). (G)-(J) Cells pre-induced for six days could express the neural cell markers $\beta$-III tubulin ((G), red), MAP2 ((H), green), GFAP ((I), green), and the synaptic marker synapsin I $((\mathrm{J})$, green) during culture in differentiation medium. Nuclei were counterstained with blue Hoechst. All scale bars are $20 \mu \mathrm{M}$.

chymal stem cell marker CD73 (94.7\%) and the NSC marker nestin (81.4\%). A smaller fraction expressed the neural precursor cell and mesenchymal cell marker vimentin $(30.8 \%)$, while none expressed the neural cell markers MAP2 or GFAP (Figure 4(A)). Daily assess- ment of marker expression during seven days of preinduction in NSC medium showed that CD73 expression was maintained, while MAP2 and GFAP were still not expressed (Figure 4(A)). No statistically significant difference in the expression of CD73, MAP2, and GFAP 
was found between days in NSC medium $(\mathrm{n}=3, P>$ 0.05) (Figure 4(A)). During the first three days of pre-induction, the expression levels of nestin $(80.5 \% \pm$ $0.98 \%$ of all cells) and vimentin $(34.5 \% \pm 1.08 \%)$ were stable $(\mathrm{n}=3, P>0.05)$. From day 3 to day 7 , however, the expression of nestin and vimentin fluctuated. Nestin expression was $74.5 \% \pm 0.91 \%$ on day $4,71.2 \% \pm 1.09 \%$ on day 5 , and $79.6 \% \pm 0.86 \%$ on day 6 , before decreasing again on day $7(60.9 \% \pm 1.39 \%)$. Vimentin expression first increased from day 3 to $4(44.5 \% \pm 2.05 \%)$, decreased from day 4 to $5(20.5 \% \pm 1.18 \%)$, increased from day 5 to $6(26.6 \% \pm 1.68 \%)$, then decreased again from day 6 to $7(18.5 \% \pm 0.68 \%)$. Changes in expression of both proteins were statistically significant between days (n $=3, P<0.001)$ (Figure 4(A)).

Prior to cell transplantation in vivo, the expression of the immunogenic markers HLA-I and HLA-DR were also detected in hEMSCPCs by flow cytometry. When cultured in the growth medium, the hEMSCPCs mode- rately expressed HLA-I (35.3\%) but not HLA-DR (Figure 4(B)). After pre-induction for four days, they continued to moderately express HLA-I (38.4\%) but not HLA-DR, indicating that hEMSCPCs retained the same immunogenic status in NSC medium (Figure 4(C)). In addition, hEMSCPCs were also stained with CM-DiI prior to cell transplantation in vivo. Staining efficiency was assessed by flow cytometry and revealed a labeling rate of $99.7 \%$ (Figure 4(D)).

\subsection{Migration and Differentiation of Transplanted hEMSCPCs in the Retinas of Nude Mice}

To examine neural differentiation in vivo, CM-DiIstained hEMSCPCs were implanted into the vitreous cavities of nude mice. Two groups of cells were transplanted, hEMSCPCs pre-induced in the NSC medium for four days (group A) and hEMSCPCs cultured in the

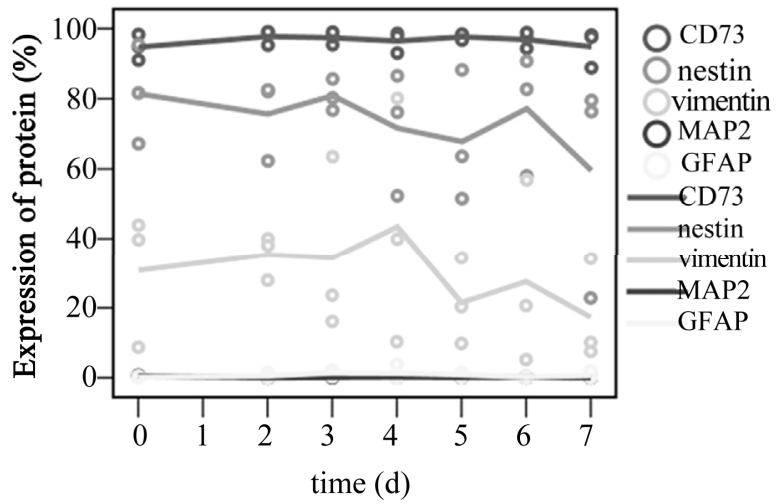

(A)

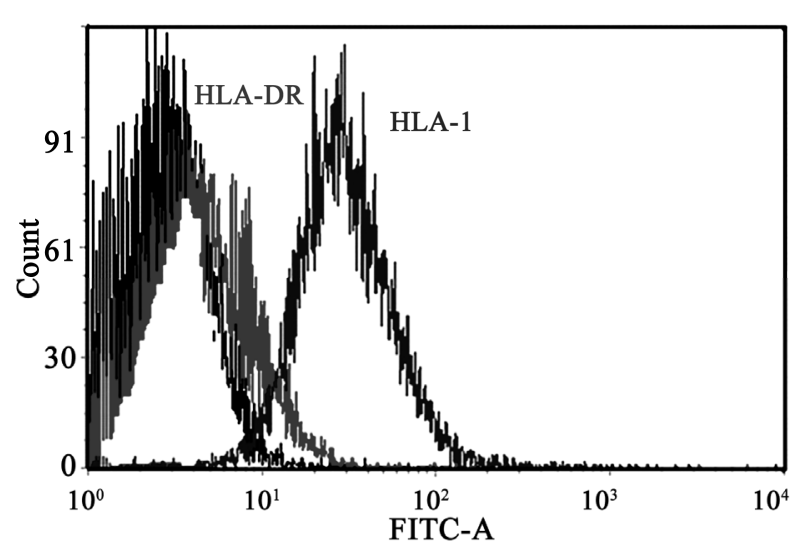

(C)

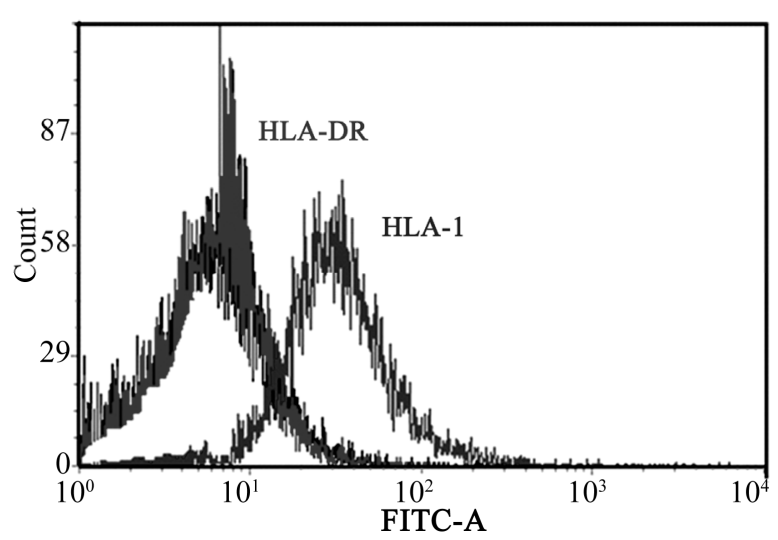

(B)

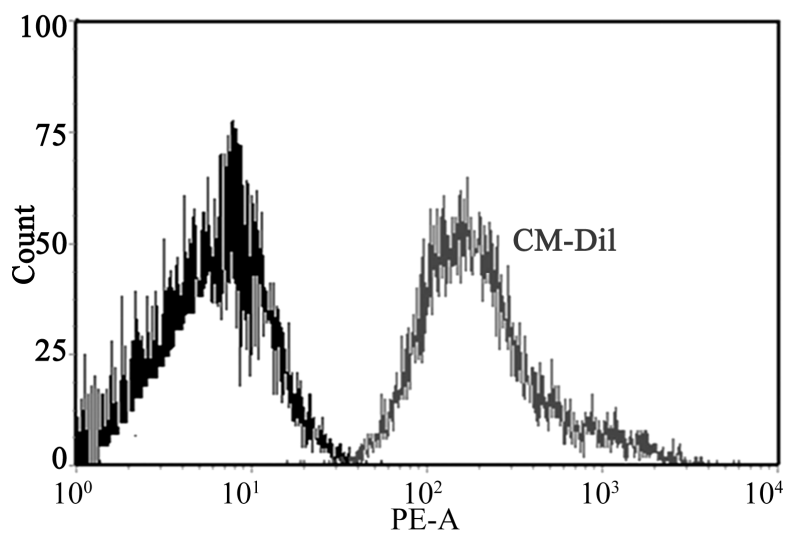

(D)

Figure 4. Flow cytometry analysis of cell-specific marker expression. (A) Cell-specific markers (CD73-blue, nestin-cyan, vimentin-gray, MAP2-purple, GFAP-yellow) expressed by hEMSCPCs. During seven days in NSC medium, most hEMSCPCs stably expressed CD73 and nestin, few expressed vimentin, while none expressed MAP2 or GFAP. (B) In growth medium, hEMSCPCs moderately expressed HLA-I (35.3\% of cells) but not HLA-DR. (C) After four days in NSC medium, hEMSCPCs still moderately expressed HLA-I (38.4\%) but not HLA-DR. (D) The efficiency of CM-DiI labeling prior to transplantation was up to $99.7 \%$. 
growth medium but not pre-induced in the NSC medium (group B). Cells of the two groups were separately transplanted into the vitreous cavities of nude mice. Four weeks later, migration and differentiation in the retina were assessed by immunostaining in frozen sections of the eyes. The retinas of normal uninjected nude mice were clear and regular, with no fluorescent (red- or green-labeled) cells (Figure 5(A)). In mice injected with group A cells, five of six experimental eyes showed migration of transplanted cells after four weeks (Figures 5(B)-(F)). In addition, pre-induced CM-DiI-stained cells expressed the NSC marker nestin and the neural cell markers $\beta$-III tubulin and GFAP (Figures 5(I)-(K)), but not MAP2 (data not shown). In mice injected with group $B$ cells, however, only one of six experimental eyes showed migration of transplanted cells (Figures 5(G) and $\mathbf{( H )})$ as well as expression of $\beta$-III tubulin (Figure 5(L)). No nestin-, MAP2-, or GFAP-positive cells were found (data not shown). Cells of group A exhibited superior migration and differentiation compared to cells of group B. In both experimental groups, no transplanted cells expressed the photoreceptor cell marker rhodopsin (data not shown). The transplanted cells that migrated into the retinas presented as either single cells or as agglomerates (Figures 5(B)-(H)). Most cells concentrated in the subretinal cavities, the retinal pigment epithelium (RPE) layer, and other nearby areas (Figures 5(D)-(F), and 5(H)). Thus, injected cells migrated across all retinal layers to reach the RPE.

\section{DISCUSSION}

The shear size and reparative capacity of human skin makes it an ideal source of pluripotent cells for research and possible autologous cell-based therapies. As a first step toward utilizing these pluripotent cells for neural regeneration therapy, we developed a two step-culture method that gradually induced the appearance of a neural-like morphology and the expression of several neural-specific cell markers. When introduced into the retina, cells from the first culture step (pre-induction) migrated cross multiple cell layers and expressed neural-specific cell markers. Although they were not functionally integrated into the healthy retina (at least after four weeks), it is possible that these pre-neural-like cells may be induced to replenish lost cells in the degenerating or damage retina, such as photoreceptor cells. The capacity of these hEMSCPCs to express neuron-like and glia-like phenotypes in vitro and in vivo suggests that these cells are a potential source for neural stem cells to repair damaged neural tissue.

A number of research groups have isolated precursor cells from skin and shown that these cells can differentiate into multiple cell types under appropriate conditions. Miller et al. [27,31,43-49] isolated precursors from neo- natal mammalian skin that could differentiate into other cell types, and even mediate regeneration after injury in animal models. They retained a normal karyotype and capacity to differentiate even after regular passage for one year in vitro, but pluripotency was markedly lower in skin-derived precursors from adult mammals. Furthermore, the biosafety of adult-derived cells is unknown. Katsuoka et al. [33-35,50-52] isolated a population of stem cells from mammalian dermal hair-follicles that could also differentiate into other cell types and promote regeneration after injury, but they were difficult to isolate in sufficient quantities for clinical applications. In contrast, the hEMSCPCs that we isolated from adult human epidermis were easily obtained in large quantities, could be continuously passaged over fifty times without changes to the normal karyotype, and demonstrate good biosafety in vitro [39].

The growth patterns of hEMSCPCs changed markedly when cultured in NSC medium; individual cells coalesced into dense, highly light-reflective spheres. Spindle-shaped cells educed from these spheres began to spread out so that the aggregates resembled neural rosettes. Once these cells were cultured in a conditioned differentiation medium, many differentiated into cells with a neural phenotype. Some cells grew slender projections with inflated or claw-like ends that contacted the soma or projections of other cells as revealed by the cell tracker CM-DiI, a lipid soluble biomembrane stain that stably labels growing cells for clear imaging of fine morphological features [40-42]. Many also expressed neuronal or glial markers, including $\beta$-III tubulin, MAP2, GFAP, and synapsin I. Flow cytometry and immunofluorescence staining showed that hEMSCPCs expressed the NSC marker nestin, the neural precursor and mesenchymal cell marker vimentin, but not the neural cell markers $\beta$-III tubulin, MAP2, GFAP, or synapsin I during sequential culture in the growth medium and NSC medium. However, expression of neural cell markers was dependent on pre-induction in NSC medium, as hEMSCPCs cultured only in differentiation medium did not express neural markers $(\beta$-III tubulin, MAP2, GFAP, or synapsin I). Moreover, uninduced cells showed inferior migration and differentiation compared to pre-induced cells after transplantation into the vitreous cavities of nude mice. Thus, pre-induction did not markedly alter neural marker expression in hEMSCPCs but was necessary to allow differentiation in a special conditioned medium and in the mouse eye (part of the central nervous system).

Flow cytometry was used to quantify the expression of cell-specific markers. The cell surface glucoprotein CD73 is a marker for mesenchymal stem cells [53]. Nestin is a class VI intermediate filament protein once thought to be a specific marker of NSCs, but recent re- 

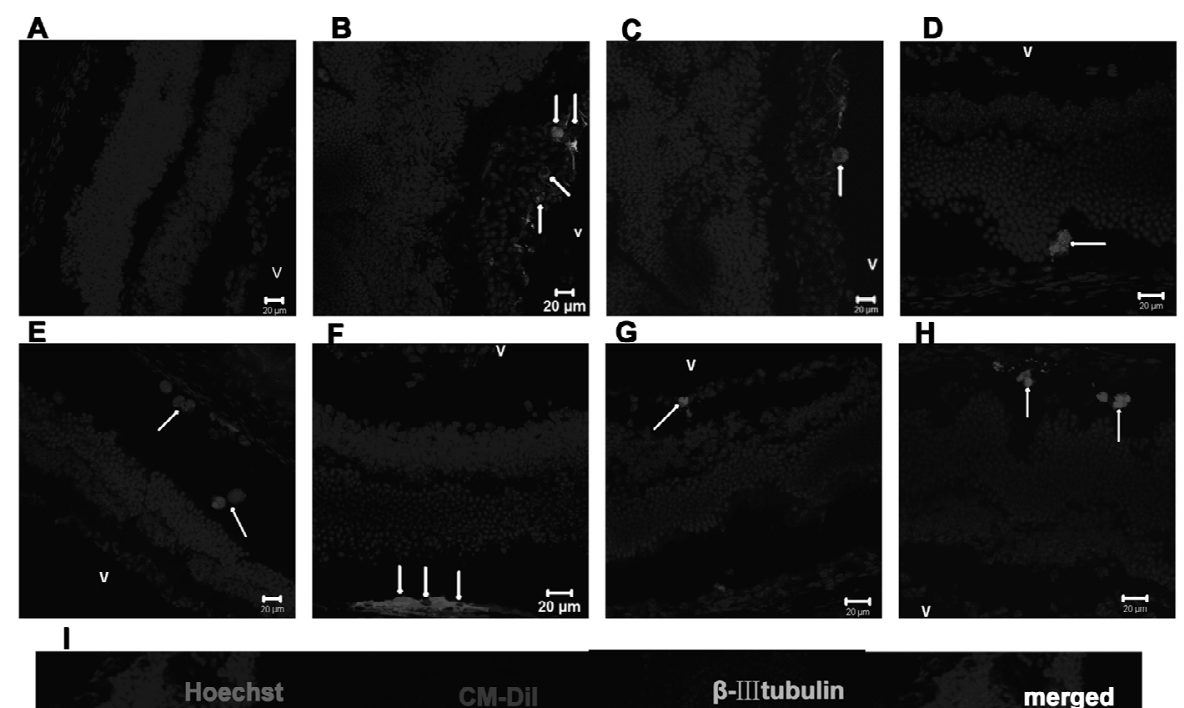

CMDII

B-IIItubulin

merged
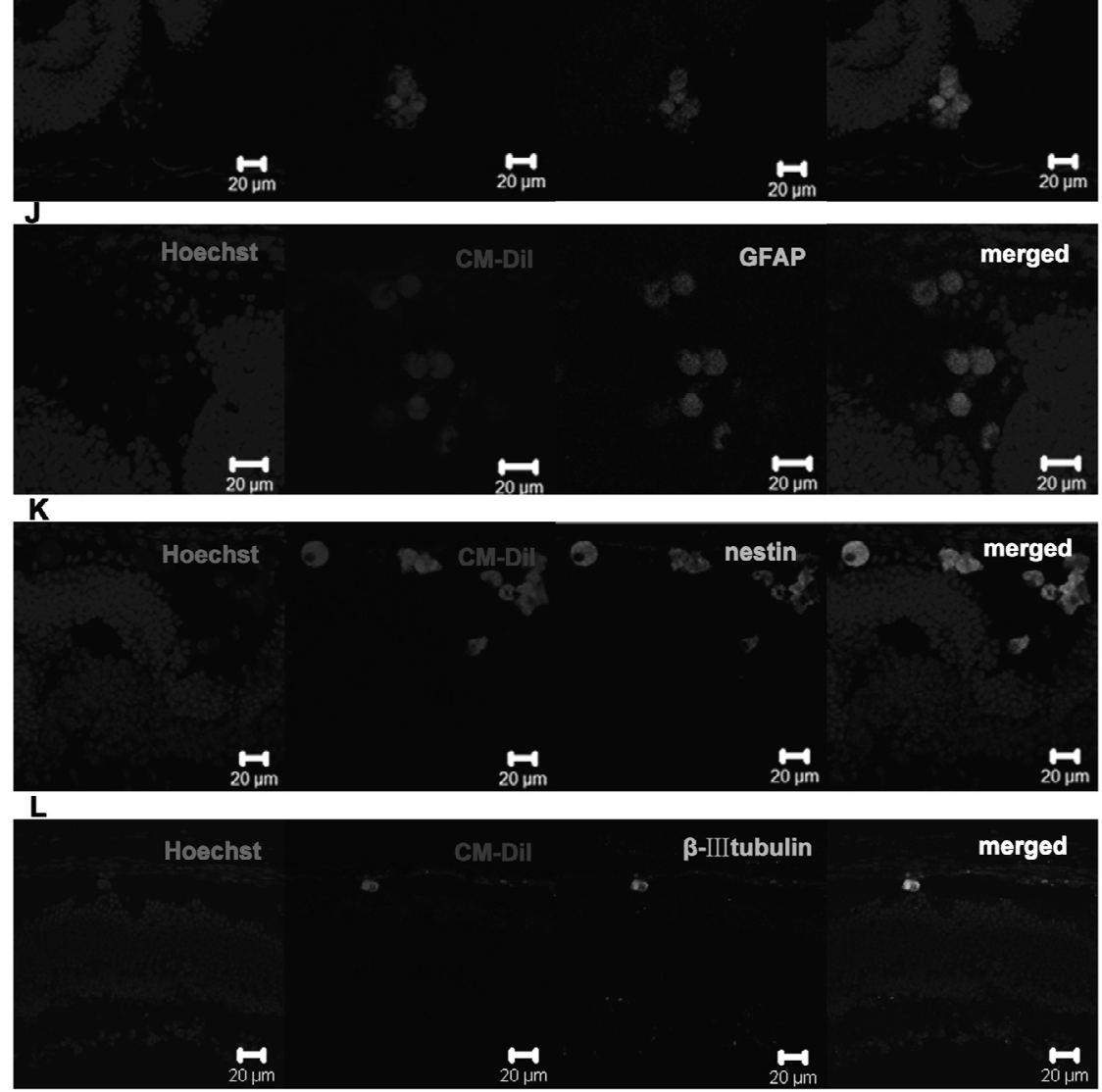

Figure 5. Migration and differentiation of transplanted hEMSCPCs in the retinas of nude mice. (A) The retinas of normal nude mice were clear and regular, and no red- or green-labeled cells were observed. (B)-(L) Four weeks after transplantation into the vitreous cavities of nude mice, many pre-induced hEMSCPCs (white arrows) had migrated into the retinal ganglion cell layer (B), (C), the sub-retinal space (D), (E), and the retinal pigment epithelium layer $(\mathrm{E}),(\mathrm{F})$. In addition, pre-induced cells expressed $\beta$-III tubulin (I), GFAP (J), and nestin (K). Transplanted cells that had not been pre-induced by NSC medium in vitro (white arrows) could migrate into the retinal ganglion cell layer $(\mathrm{G})$ and the sub-retinal space $(\mathrm{H})$, and express $\beta$-III tubulin $(\mathrm{L})$. "V" represents the vitreous cavities or nearby areas. Nuclei were counterstained with blue Hoechst. All scale bars represent $20 \mu \mathrm{M}$. 
ports indicated that it is also expressed by multipotent precursor cells and that expression correlates with the potential for proliferation, migration, and differentiation $[54,55]$. Vimentin is a class III intermediate filament protein and a marker for neural precursor cells and mesenchymal-derived cells [56-59]. MAP2 is a mature neuronal marker, while the intermediate filament protein GFAP is expressed almost exclusively by astrocytes. Flow cytometry showed that the expression levels of these markers by hEMSCPCs were not significantly changed during culture in growth medium or brief (2 - 3 day) culture in NSC medium. However, from the 3rd to 7th day in NSC medium, expression of nestin and vimentin began to fluctuate, possibly indicating the beginning of a phenotypic transition. However, hEMSCPCs pre-induced in NSC medium grew slender projections that could be easily sheared off the soma during harvesting for flow cytometry, so this fluctuation in expression may reflect variable loss of markers localized to processes. A more accurate determination of marker expression patterns during NSC culture will require the use of alternative methods like real time PCR or Western blotting.

Approximately the same percentage of pre-induced and uninduced hEMSCPCs expressed HLA-I, indicating that these cells have a stable immunogenicity. Nude mice were chosen for hEMSCPC transplantation experiments because they are immunologically defective and so would not generate an immune response to transplanted cells. Four weeks after injection of hEMSCPCs, both induced and uninduced CM-DiI-labeled cells had migrated primarily to the subretinal space, retinal pigment epithetlium layer, and other nearby areas. The reasons for this selective migration are still obscure. Both hEMSCPCs and retinal pigment epithelium originate from the ectoderm, and this homology may have allowed for better survival of transplanted hEMSCPCs. The subretinal cavity may also accumulate transplanted cells even in immunologically active mice because it is an immunoprivileged zone. While both induced and uninduced cells migrated, pre-induced cells showed superior migration and neural differentiation.

There were differences in neural differentiation in vitro versus in vivo. In contrast to observations in vitro, the mature neuron marker MAP-2 was not expressed by either group of transplanted hEMSCPCs, although this might reflect the short transplantation time (four weeks). In addition to common markers like MAP-2, transplanted cells did not express retina-specific markers. For example, rhodopsin, a marker of retinal photoreceptors, was not expressed by transplanted hEMSCPCs that migrated into the retina, possibly because the healthy retina releases no factors that would induce differenttiation. A longer transplantation time or induction of growth factor expression may be required for full expression of neural markers, but these questions require further study.

The epidermis is easily harvested, so hEMSCPCs may be a productive source of cells for autologous cell-based therapy against neurological diseases. Our results show that hEMSCPCs possess the capacity to differentiate into neural-like cells if pre-induced in NSC medium. Whether hEMSCPCs can replenish endogenous neural cells after induction and differentiation requires further study. To reach this goal, further studies are required to understand the neural lineage capacity of these cells, including tests of differentiation efficiency and function in vitro, and to assess the biological safety of these cells in vivo. Experiments testing the restorative efficacy of these cells in animal models of neurodegenerative diseases are clearly warranted.

\section{ACKNOWLEDGEMENTS}

We are grateful to members of the State Key Laboratory of Ophthalmology, Zhongshan Ophthalmic Center, Sun Yat-sen University, for discussion and advice. This work was supported by the Science and Technology Projects of Guangdong Province, China (2009B060600002, 2010B060500006).

\section{REFERENCES}

[1] Jiang, W. (2010) Neurology. 2nd Edition, People's Medical Publishing House, Beijing.

[2] Carsten, R.B. and Jens, C.S. (2004) Therapeutic strategies for neurodegenerative disorders: Emerging clues from Parkinson's disease. Biological Psychiatry, 56, 213-216. doi:10.1016/j.biopsych.2003.12.025

[3] John, B.S. (2004) Pharmacotherapeutic approaches to the treatment of Alzheimer's disease. Clinical Therapeutics, 26, 615-630. doi:10.1016/S0149-2918(04)90064-1

[4] Zhou, J.W. (2010) Recent progress in neurodegenerative disorder research in China. Science China Life Sciences, 53, 348-355. doi:10.1007/s11427-010-0061-0

[5] Peng, L.S. and Li, C.R. (2009) RNA interference and neural degenerative diseases. West China Medical Journal, 21, 1806-1808.

[6] William, J.M., Raymond, T.B., Joao, S., et al. (2010) Gene delivery of AAV2-neurturin for Parkinson's disease: A double-blind, randomised, controlled trial. The Lancet Neurology, 9, 1164-1172. doi:10.1016/S1474-4422(10)70254-4

[7] Wu, J.J., Yu, W.B., Chen, Y., et al. (2010) Intrastriatal transplantation of GDNF-engineered BMSCs and its neuroprotection in Lactacystin-induced Parkinsonian Rat Model. Neurochemical Research, 35, 495-502. doi:10.1007/s11064-009-0086-6

[8] William, J.M., Jill, L.O., Leonard, V., et al. (2008) Safety and tolerability of intraputaminal delivery of CERE-120 (adeno-associated virus serotype 2-neurturin) to patients with idiopathic Parkinson's disease: An open-label, phase 
I trial. The Lancet Neurology, 7, 400-408. doi:10.1016/S1474-4422(08)70065-6

[9] Kerri, S. (2010) Treatment frontiers. Nature, 466, S15S18. doi:10.1038/nature09476

[10] Jiao, J.W. (2010) Embryonic and adult neural stem cell research in China. Science China Life Sciences, 53, 338341. doi:10.1007/s11427-010-0070-Z

[11] Stefano, P., Lucia, Z., Michela, D. and Gianvito, M. (2005) Neural stem cells and their use as therapeutic too in neurological disorders. Brain Research Reviews, 48, 211-219. doi:10.1016/j.brainresrev.2004.12.011.

[12] Gu, Y., Hu, N., Liu, J., et al. (2010) Isolation and differentiation of neural stem/progenitor cells from fetal rat dorsal root ganglia. Science China Life Sciences, 53, 1057-1064. doi:10.1007/s11427-010-4053-x

[13] Keun-Hwa, J., Kon, C., Soon-Tae, L., et al. (2008) Identification of neuronal outgrowth cells from peripheral blood of stroke patients. Annals of Neurology, 63, 312322. doi:10.1002/ana.21303

[14] Sarugaser, R., Ennis, J., Stanford, W.L. and Gianvito, M. (2009) Isolation, propagation, and characterization of human umbilical cord perivascular cells (HUCPVCs). $\mathrm{Me}$ thods in Molecular Biology, 482, 269-279. doi:10.1007/978-1-59745-060-7-17

[15] Lin-ya, H., Jia-lin, Y., Fang, L., et al. (2009) Synapse function of neuron-like cells induced from mesenchymal stem cells by Salvia miltiorrhiza. Acta Academiae Medicinae Militaris Tertiae, 31, 144-147. doi:1000-5404(2009)02-0144-04

[16] Shi, Y.F., Hu, G.Z., Su, J.J., et al. (2010) Mesenchymal stem cells: A new strategy for immunosuppression and tissue repair. Cell Research, 20, 510-518. doi:10.1038/cr.2010.44

[17] Wu, L., Chen, R.K., Yang, L., et al. (2009) Differentiation of adipose-derived stem cells into nerve stem cells across embryonic layer. Fourth Military Medical University, 30, 70-72. doi:1000-2790(2009)01-0070-03

[18] Stefan, A., Helmut, K., Irina, S., et al. (2004) Neurally selected embryonic stem cells induce tumor formation after long-term survival following engraftment into the subretinal space. Investigative Ophthalmology \& Visual Science, 45, 4251-4255. doi:10.1167/iovs.03-1108

[19] Oscar, H.M. and Angela, N. (2010) Epithelial plasticity, stemness and pluripotency. Cell Research, 20, 1086-1088. doi:10.1038/cr.2010.127

[20] Dengke, K.M., Bonaguidi, M.A., Ming, G.L. and Song, H.J. (2009) Adult neural stem cells in the mammalian central nervous system. Cell Research, 19, 672-682. doi:10.1038/cr.2009.56

[21] Chase, L.G, Lakshmipathy, U, Solchaga, L.A., et al. (2010) A novel serum-free medium for the expansion of human mesenchymal stem cells. Stem Cell Research \& Therapy, 1, 8. doi: $10.1186 /$ scrt8

[22] Raymond, D.L., Shaomei, W., Bin, L., et al. (2007) Cells isolated from umbilical cord tissue rescue photoreceptors and visual functions in a rodent model of retinal disease. Stem Cells, 25, 602-611. doi:10.1634/stemcells.2006-0308
[23] Andrew, J.H., Isabel, Z., Henry, H.T., et al. (2009) Human umbilical cord blood-derived mesenchymal stem cells do not differentiate into neural cell types or integrate into the retina after intravitreal grafting in neonatal rats. Stem Cells and Development, 18, 399-409. doi:10.1089/scd.2008.0084

[24] Isabel, Z., Andrew, J.H., Faisal, A., et al. (2009) Umbilical cord blood mesenchymal stromal cells are neuroprotective and promote regeneration in a rat optic tract model. Experimental Neurology, 216, 439-448. doi:10.1016/j.expneurol.2008.12.028

[25] Xue, G.S., Zhang, Y. and Qi, Z.L. (2008) Current research situation of adipose-derived stem cells and its application in tissue engineering. Journal of Tissue Engineering and Reconstructive Surgery, 4, 174-176.

[26] Hideo, O., Ariane, R., Ce'cile, K., et al. (2001) Morphogenesis and renewal of hair follicles from adult multipotent stem cells. Cell, 104, 233-245. doi:10.1016/S0092-8674(01)00208-2

[27] Jean, G.T., Mahnaz, A., Karl, J.L., et al. (2001) Isolation of multipotent adult stem cells from the dermis of mammalian skin. Nature Cell Biology, 3, 778-786. doi:10.1038/ncb0901-778

[28] Young, H.E., Steele, T.A., Bray, R.A., et al. (2001) Human reserve pluripotent mesenchymal stem cells are present in the connective tissues of skeletal muscle and dermis derived from fetal, adult, and geriatric donors. Anatomy \& Physiology, 264, 51-62. doi:10.1002/ar.1128

[29] Shi, C. and Cheng, T. (2003) Effects of acute wound environment on the neonatal dermal multipotent cells. Cells Tissues Organs, 175, 177-185. doi:10.1159/000074939

[30] Shih, D.T. (2005) Isolation and characterization of neurogenic mesenchymal stem cells in human scalp tissue. Stem Cells, 23, 1012-1025. doi:10.1634/stemcells.2004-0125

[31] Jean, G.T., Ian, A.M., Darius, B. and Freda, D.M. (2005) Isolation and characterization of multipotent skin-derived precursors from human skin. Stem Cells, 23, 727-737. doi:10.1634/stemcells.2004-0134

[32] Karl, J.L. Fernandes, I.A. McKenzie, Pleasantine, M. et al. (2004) A dermal niche for multipotent adult skin-derived precursor cells. Nature Cell Biology, 6, 1082-1093. doi:10.1038/ncb1181

[33] Yasuyuki, A., Lingna, L., Kensei, K. and Robert, M.H. (2004) Multipotent hair follicle stem cells promote repair of spinal cord injury and recovery of walking function. Cell Cycle, 7, 1865-1869. doi:10.4161/cc.7.12.6056

[34] Yasuyuki, A., Lingna, L., Kensei, K., Sheldon, P. and Robert, M.H. (2005) Multipotent nestin-positive, keratinnegative hair-follicle bulge stem cells can form neurons. Proceedings of the National Academy of Sciences, 102, 5530-5534. doi:10.1073/pnas.0501263102

[35] Yasuyuki, A., Lingna, L., Raul, C., et al. (2005) Implanted hair follicle stem cells form Schwann cells that support repair of severed peripheral nerves. Proceedings of the National Academy of Sciences, 102, 17734-17738. doi:10.1073/pnas.0508440102

[36] Patrizia, T., Jeff, W.M., Maria, G.B., et al. (2006) Brain 
engraftment and therapeutic potential of stem/progenitor cells derived from mouse skin. The Journal of Gene Medicine, 8, 506-513. doi:10.1002/igm.866

[37] So, P.L. and Epstein, E.H. (2004) Adult stem cells: Capturing youth from a bulge. Trends in Biotechnology, 22, 493-496. doi:10.1016/j.tibtech.2004.08.007

[38] Morasso, M.I. and Omic-Canic, M. (2005) Epidermal stem cells: The cradle of epidermal determination, differentiation and wound healing. Biology of the Cell, 97, 173-183. doi:10.1042/BC20040098

[39] Huang, B., Li, K.J., Yu, J., et al. (2011) Generation of Human epidermis-derived mesenchymal stem cell-like pluripotent cells and their reprogramming in mouse chimeras. http://precedings.nature.com/documents/6016/version/1

[40] Yamamoto, N., Higashi, S. and Toyama, K. (1997) Stop and branch behaviors of geniculocortical axons: A timelapse study in organotypic cocultures. The Journal of Neuroscience, 17, 3653-3663.

[41] Cai, Q., Ji, M., Zhang, J., et al. (2011) Comparative study on glutamatergic synaptic connections in rat striatum with laser scanning confocal microscopy and electron microscopy. Chinese Journal of Histochemistry and Cytochemistry, 20, 236-240.

[42] Matsubayashi, Y., Iwai, L. and Kawasaki, H. (2008) Fluorescent double-labeling with carbocyanine neuronal tracing and immunohistochemistry using a cholesterol-specific detergent digitonin. Journal of Neuroscience Methods, 174, 71-81. doi:10.1016/j.jneumeth.2008.07.003

[43] Ian, A.M., Jeff, B., Jean, G.T., et al. (2006) Skin-derived precursors generate myelinating Schwann cells for the injured and dysmyelinated nervous system. Journal of Neuroscience Methods, 26, 6651-6660. doi:10.1523/JNEUROSCI.1007-06.2006

[44] Karl, J.L., Fernandes, N.R., Kobayashi, C.J. et al. (2006) Analysis of the neurogenic potential of multipotent skinderived precursors. Experimental Neurology, 201, 32-48. doi:10.1016/j.expneurol.2006.03.018

[45] Jeff, B., Joseph, S.S., Liu, J., et al. (2007) Skin-derived Precursors generate myelinating Schwann cells that promote remyelination and functional recovery after contusion spinal cord injury. Journal of Neuroscience Methods, 27, 9545-9559. doi:10.1523/JNEUROSCI.1930-07.2007

[46] Karl, J.L., Jean, G.T. and Freda, D.M. (2008) Multipotent skin-derived precursors: Adult neural crest-related precursors with therapeutic potential. Philosophical Transactions of the Royal Society B, 363, 185-198. doi:10.1098/rstb.2006.2020

[47] Jean-Francois, L., Jeffrey, A.B., Yan, C., et al. (2009) Skin-derived precursors differentiate into skeletogenic cell types and contribute to bone repair. Stem Cells and Development, 18, 893-905. doi:10.1089/scd.2008.0260
[48] Jeffrey, B., Maryline, P., Olena, M., et al. (2009) SKPs derive from hair follicle precursors and exhibit properties of adult dermal stem cells. Cell Stem Cell, 5, 610-623. doi:10.1016/j.stem.2009.10.019

[49] Hiroyuki, J., Olena, M., Jones, K.L., et al. (2010) Convergent genesis of an adult neural crest-like dermal stem cell from distinct developmental origins. Stem Cells, 28, 2027-2040. doi:10.1002/stem.525

[50] Yasuyuki, A., Lingna, L., Kensei, K. and Robert, M.H. (2010) Embryonic development of hair follicle pluripotent stem (hfPS) cells. Medical Molecular Morphology, 43, 123-127. doi:10.1007/s00795-010-0498-z

[51] Yasuyuki, A., Kensei, K., Robert, M.H. (2010) The advantages of hair follicle pluripotent stem cells over embryonic stem cells and induced pluripotent stem cells for regenerative medicine. Journal of Dermatological Science, 60, 131-137. doi:10.1016/j.jdermsci.2010.09.007

[52] Fang, L., Aisada, U., Hiroaki, K., et al. (2010) The bulge area is the major hair follicle source of nestin-expressing pluripotent stem cells which can repair the spinal cord compared to the dermal papilla. Cell Cycle, 10, 830-839. doi:10.4161/cc.10.5.14969

[53] Florian, H., Wolf, C.P., David, A., et al. (2009) Morphological and immunocytochemical characteristics indicate the yield of early progenitors and represent a quality control for human mesenchymal stem cell culturing. Journal of Anatomy, 214, 759-767. doi:10.1111/i.1469-7580.2009.01065.x

[54] Su, P.H., Wang, T.C., Wong, Z.R., et al. (2011) The expression of nestin delineates skeletal muscle differentiation in the developing rat esophagus. Journal of Anatomy, 218, 311-323. doi:10.1111/j.1469-7580.2010.01331.x.

[55] Svachovaa, H., Pour, L., Sana, J., et al. (2011) Stem cell marker nestin is expressed in plasma cells of multiple myeloma patients. Leukemia Research, 35, 1008-1013. doi:10.1016/j.leukres.2011.03.001

[56] Frederiksen, K. and McKay, R.D.G. (1988) Proliferation and differentiation of rat neuroepithelial precursor cells in vivo. The Journal of Neuroscience, 8, 1144-1151.

[57] Yvan, A., Jean-Guy, V., Jean-Francois, B., et al. (2001) Isolation of multipotent neural precursors residing in the cortex of the adult human brain. Experimental Neurology, 170, 48-62. doi:10.1006/exnr.2001.7691

[58] Jahan, A., Saskia, F., Anli, Z. and Melissa, F. (2010) Characterization of neural stem/progenitor cells expressing VEGF and its receptors in the subventricular zone of newborn piglet brain. Neurochemical Research, 35, 14551470. doi:10.1007/s11064-010-0207-2

[59] Chanchai, B., Kerstin, K., Sombat B., et al. (2011) Fibrosis and evidence for epithelial-mesenchymal transition in the kidneys of patients with staghorn calculi. British Journal of Urology International, 107, 1847. doi:10.1111/j.1464-410X.2011.10350.x 